\title{
MONITORING OF SURFACE WATER RESOURCES IN THE MINAB PLAIN BY USING THE STANDARDIZED PRECIPITATION INDEX (SPI) AND THE MARKOF CHAIN MODEL
}

\author{
Bahari Meymandi.A \\ Department of Hydraulic Structures, college of civil, Bandar Abbas Branch, Islamic Azad University, \\ Bandar Abbas, Iran \\ Angebini S. \\ Associate Professor Department of Civil Engineering, Bandar Abbas Branch, Islamic Azad \\ University, Bandar Abbas, Iran
}

\begin{abstract}
Increase or decrease in rainfall compared to normal conditions, one can increase the flood risk, The second cause is drought consequences of different economic and social consequences. Knowing the probability distribution of rainfall provides sufficient grounds for water resources planning. This knowledge will be possible with the help of statistical methods and dynamic. In this paper, by using Markov chain and SPI index Likely very dry to very humid conditions, based on annual rainfall Minab Basin rain gauge stations were calculated. The basin hydrological drought Brntyn station using long-term data were analyzed and monitored. The results suggest probability of transition from one mode to the other conditions specified in the same state is more likely crossing. Drought Forecast water using Markov chain for 2015-2016 years is $88.8 \%$ likely indicates dry conditions.
\end{abstract}

Keywords: Drought, Markov chain index, SPI, Minab River

\section{INTRODUCTION}

Considering because of exposure latitude 25 degrees north to 40 is considered one of the world's arid and semi-arid countries. That's why from time to time, especially drought, extreme weather anomalies are seen. The geographical conditions of the domination of the subtropical high pressure systems were in Iran And these systems due to the continued decline and subsidence air mass associated generally clear and sunny sky Heated and drought have exacerbated the ground. In addition, the dominance of the barrier system climbs a humid, unstable and totally rule it reduces rainfall in the region (the disciple and Paymzd, 2011). Drought as one of the most important natural disasters, in the form of shortage of rainfall and rising temperatures, The efficiency of human activities in various fields of socio - economic and cultural welcomes stagnated. There is a clear difference between dryness and drought. Land, feature in the area is inadequate amount of rainfall that is permanent. In contrast, a temporary meteorological drought in a region, and only when the amount is below normal rainfall occurs. The degree of influence, occurrence of drought in different time periods for a zone is not the same. So that in some periods of higher intensity and longer periods of less intense. Therefore, to determine the rankings for a period of drought can be used for a station, Fluctuations in climate weather station to be identified for several years. So that, if the calculated is parameters a decrease (increase). This situation reflects the trend towards hot dry weather (cold and wet) is. According to the province in the arid and semi-arid climatic regions of Iran and repeated droughts in recent years, The importance of addressing the issue of drought is inevitable Studied in this report is the province's political boundaries An area of about 70,000 square kilometers to cover. In an effort to precise definition and assessment of drought, profiles and models various models presented.

Limited economic water supply to keep pace with population growth and increased demand And its excessive use in agriculture than in other sectors has led Water shortage has become an exact representation And experts drawn from the minds of many. This, in recent years the country has faced 
periodic droughts, is evident (Alizadeh, 2001). The drought assessment to determine the proper set of indicators is of particular importance. Drought indices using the intensity, duration and extent of drought had little And periodically evaluated. Several criteria are used to assess drought .Among them, the standardized precipitation index (SPI) and Markov chain in regional analysis of drought And comparative studies and the most common comparison between different regions And high capability has been shown in many studies.

\section{THE MODEL USED IN THIS STUDY Markov Chain Model}

A system like the one above that at $S_{1}, \ldots, S_{N}$ any moment one of the distinct states considers. In discrete time intervals and at regular intervals, the system is changed according to a set of possibilities. For $t=1,2, \ldots$ durations $t$ with qt show at the moment. For a good description of the current system needs to know the current state along with all previous cases. For a special case of the first order Markov chain, Probabilistic description of the current and previous state is determined only by the state.

\section{Standardized precipitation indexes}

In 1993 this index MacKay bid. The lack of rainfall is calculated from multiple time scales (3, 6, 12, 24 and 48 months). The results of the index of confidence is particularly important for water resources And is based only on rainfall data. The index in the short period of time suitable for farming and soil moisture available to plants. Long-term time scales to study river flows and underground water reservoirs is important

\section{MATERIALS AND METHODS}

\section{The study area}

Minab catchment area in east longitude 65 degrees 6 minutes and 65 degrees latitude 65 degrees 66 minutes $\mathrm{Wu}$ to 62 degrees and 03 minutes is located. These range from political divisions located in Hormozgan Province. And from the north to River basin Halil Roud, south of the city of Minab(north of the Strait of Hormuz ). From the East to Karyan bassin , and from West basin to basin Hassan Langi limits (Figure 1). 


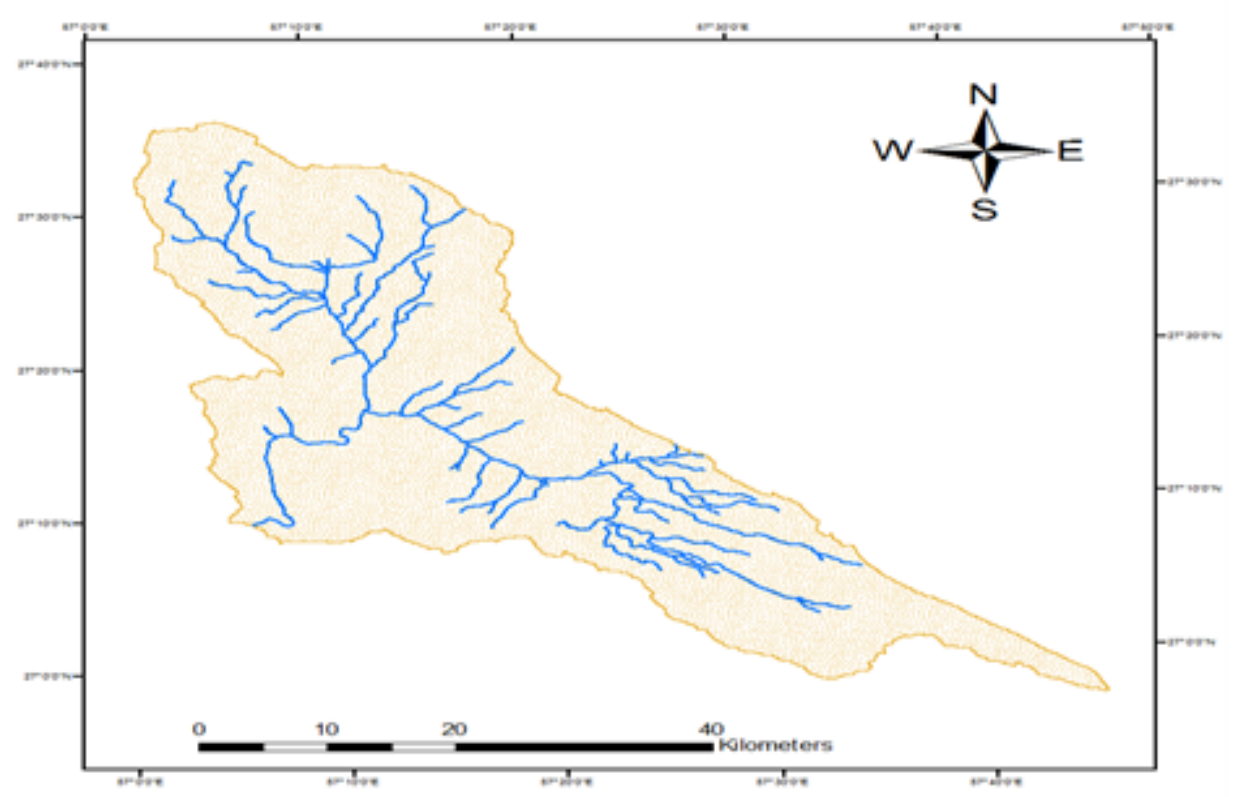

Figure 1: within the catchment area of the dam independence of the branches Minab Minab

\section{Reconstruction And Homogeneity Test Data}

In this study, data from the Ministry of Energy of monthly precipitation stations in Hormozgan Minab river basin water year 2014-2015 were collected from beginning to end, Ron homogeneity test was used to test data and supplementary information, and to extend the length difference method and ratios, respectively. Then a subscriber base of meteorological stations was selected as 1973-2015. Then, using standardized precipitation index and the Markov chain drought monitoring And predicted that in the next ten years were studied. In total 16 stations in the basin are studied rainfall data The period from 8 to 50 years is different.

\section{RESULTS}

\section{Meteorological Drought}

Drought zoning maps, Precipitation data from 16 meteorological stations Ministry of Energy and a gauging station was used. Map 2 shows the location of Minab Basin that its output is Brntyn hydrometric station. 


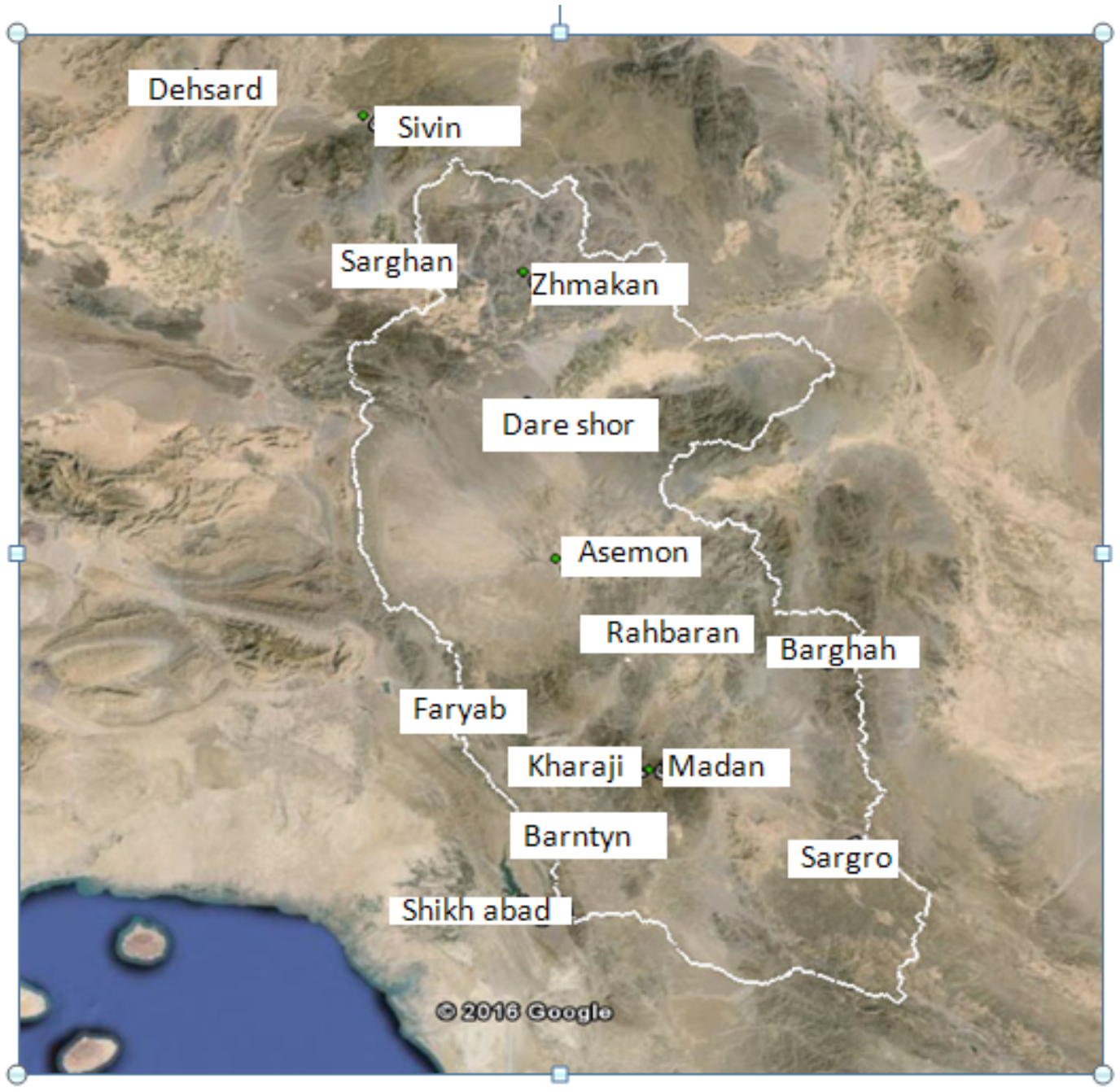

Figure 2: Location of stations Minab Basin

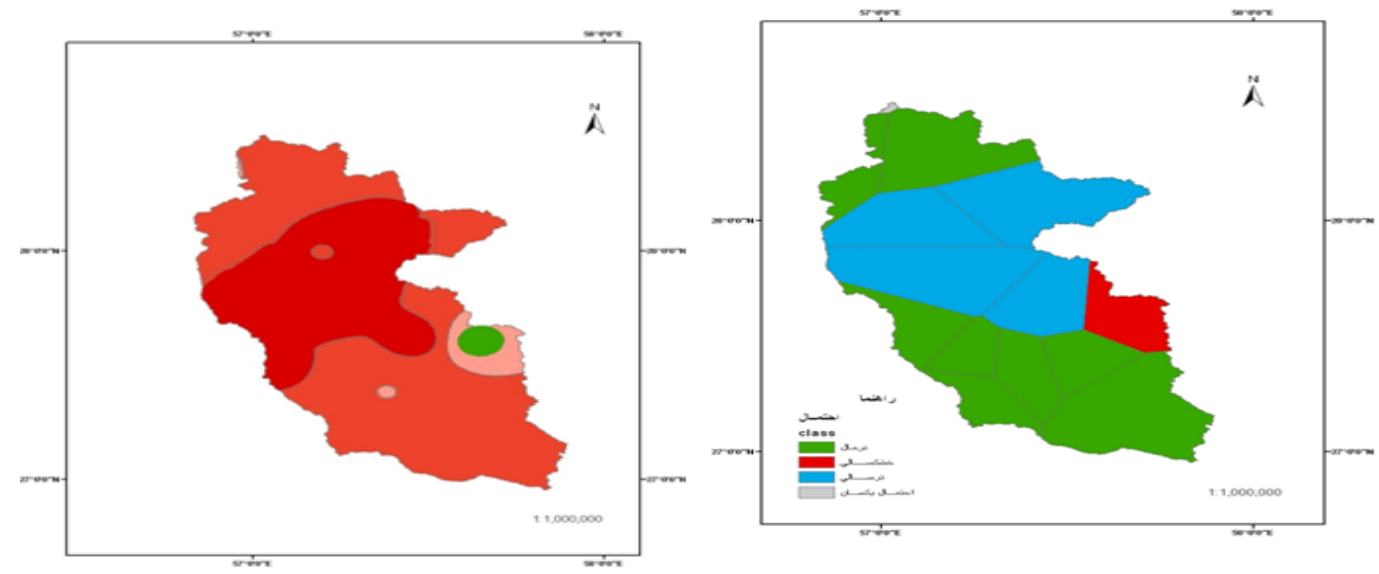

Figure 3: real situation of drought in years 2005-2006 and Figure 4: The possibility of different modes in years 2005-2006 

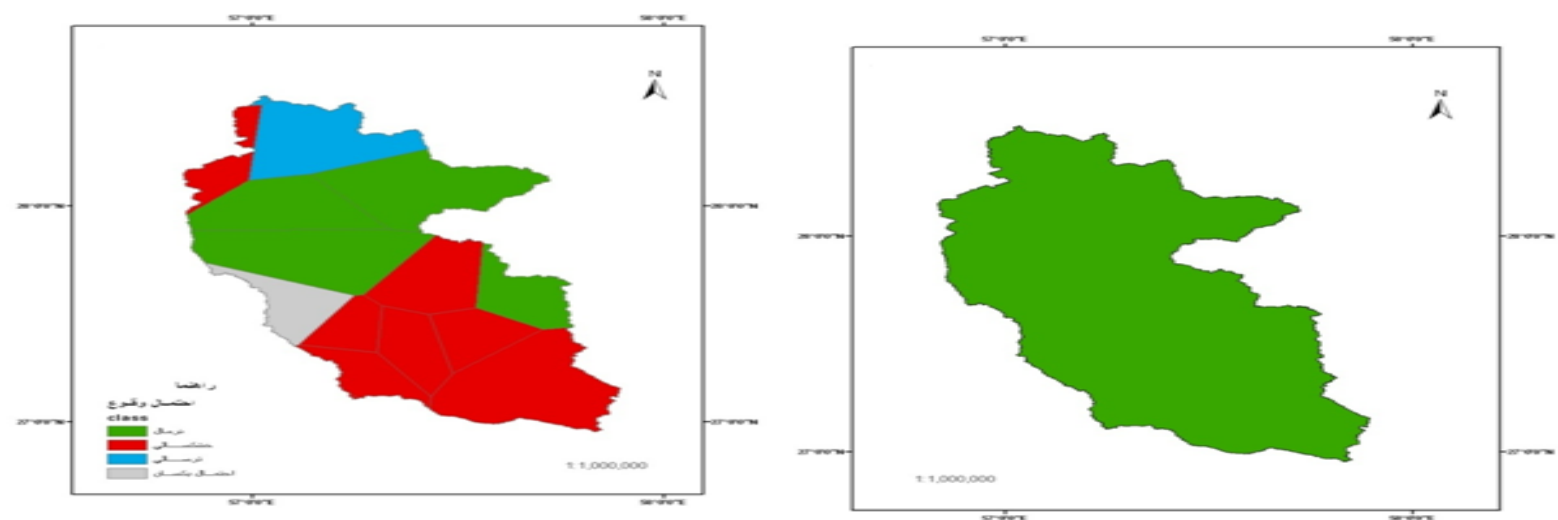

Figure 5: real situation of drought in years 2006-2007 and Figure 6: The possibility of different modes in years 2006-2007
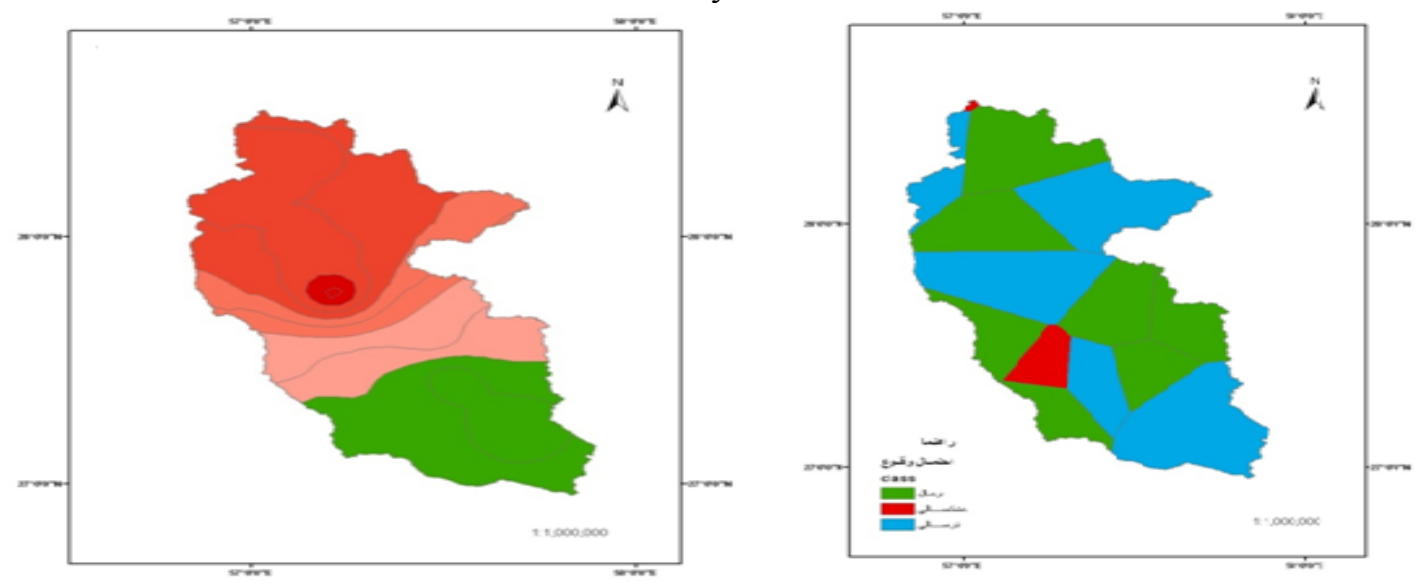

Figure 7: real situation of drought in years 2007-2008 and Figure 8: The possibility of different modes in years 2007-2008
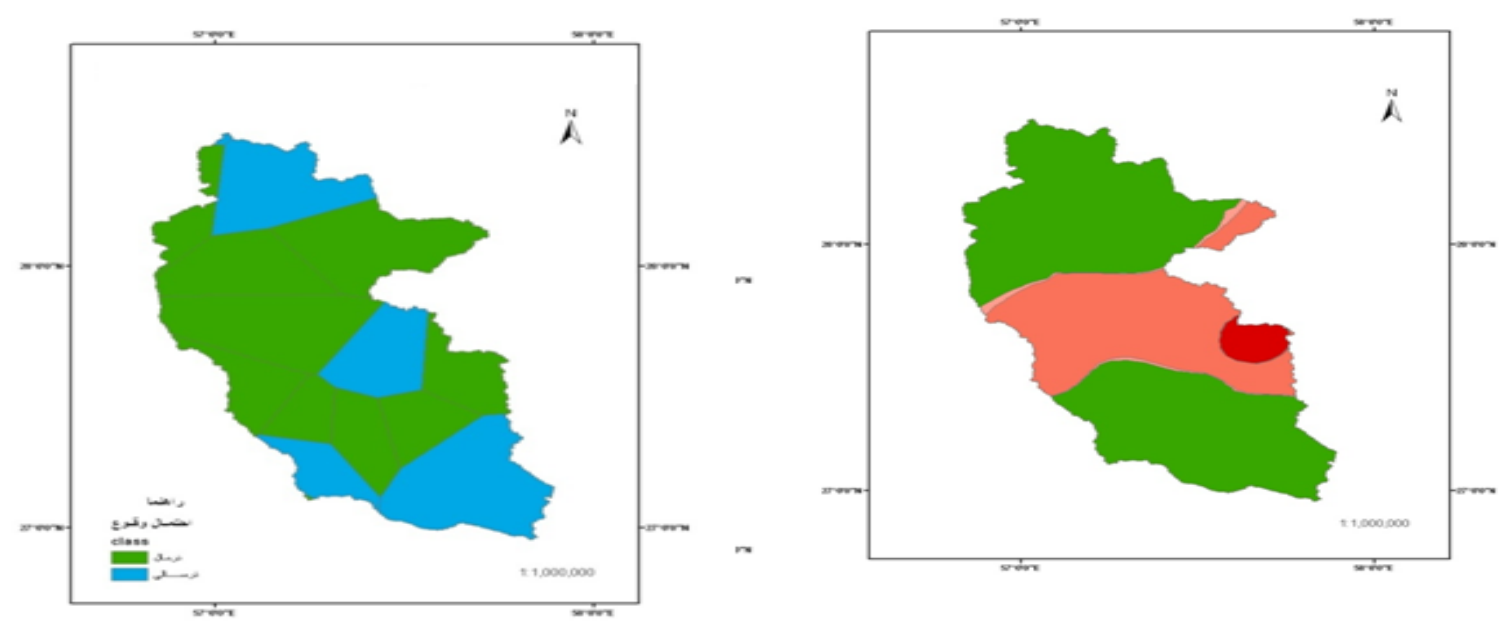

Figure 9: the real situation of drought in years 2009-2010 and Figure 10: probability of different modes 2009-2010

Table 1: Ranking of statistical years of drought status

\begin{tabular}{|c|c|c|}
\hline water year & $\begin{array}{c}\text { The SPI index } \\
\text { average }\end{array}$ & condition \\
\hline $2003-2004$ & -1.81 & Drought \\
\hline $2000-2001$ & -1.38 & Drought \\
\hline $84-85$ & -1.25 & Drought \\
\hline
\end{tabular}




\begin{tabular}{|c|c|c}
\hline $1983-1984$ & -1.09 & Drought \\
\hline $1993-1994$ & -1.06 & Drought \\
\hline $2011-2012$ & -0.97 & normal \\
\hline $1985-1986$ & -0.78 & normal \\
\hline $2007-2008$ & -0.74 & normal \\
\hline $1980-1981$ & -0.74 & normal \\
\hline $2002-2003$ & -0.72 & normal \\
\hline $1984-1985$ & -0.67 & normal \\
\hline $2006-2007$ & -0.05 & normal \\
\hline $1998-1999$ & -0.03 & normal \\
\hline $2010-2011$ & 0.12 & normal \\
\hline $1975-1976$ & 1.57 & Wet \\
\hline $1992-1993$ & 1.84 & Wet \\
\hline $1994-1995$ & 1.99 & Wet \\
\hline
\end{tabular}

\section{Hydrological drought}

There are three hydrometric stations in the basin Minab. Brntyn station just across the river from these three stations has long-term replacement for analysis. Hydrological drought is analyzed. Sarkom station with 13 years Statistics. Brntyn station on the River Jaghin with 17 years Maraz not appropriate period. The average monthly discharge Brntyn (in million cubic meters) Was used to calculate the SPI index. The results are shown in Table 2. Table 2 drought-wet condition of the water in the river Minab shows per year. As seen in the table 2006-2005 and 2012-2011 and 2014-2015 years the river has experienced severe drought conditions. Monitoring shows that the two types of drought Hydrological drought and do not necessarily match.

Table 2: Comparison of two droughts

\begin{tabular}{|c|c|r}
\hline Hydrological drought & Meteorological drought & water year \\
\hline Drought & normal & $2001-2002$ \\
\hline Drought & normal & $2002-2003$ \\
\hline Drought & Drought & $2003-2004$ \\
\hline normal & Wet & $2004-2005$ \\
\hline Drought & Drought & $2005-2006$ \\
\hline Drought & normal & $2006-2007$ \\
\hline Drought & normal & $2007-2008$ \\
\hline Drought & normal & $2008-2009$ \\
\hline normal & normal & $2009-2010$ \\
\hline Drought & normal & $2011-2012$ \\
\hline Drought & normal & $2012-2013$ \\
\hline Drought & normal & $2013-2014$ \\
\hline
\end{tabular}




\section{CONCLUSION}

In this study, using a meteorological drought index drought conditions. And zoning in the province (SPI) standard is evaluated Minab city And then uses the first order Markov chain to forecast droughts were the following results were obtained. Due to the fact that the number of years is statistically more stations Markov Chain Forecasting closer to the actual situation. Tables comparing actual and forecast in the last ten years. Rate of occurrence in the basin were taken. As can be seen Beginning in the early years predict that it is 2005-2006 Markov Chain Forecasting is a large difference between reality .But gradually with the years of statistical prediction is closer to the actual situation. Even in cases where a year was wet condition And in the years immediately following the drought situation in the state, Chain failed to correctly predict status. Examples 2013-2014 and 2014-2015 is two years. The actual situation of the wet form of consecutive drought has changed And the prediction was incorrect chain.

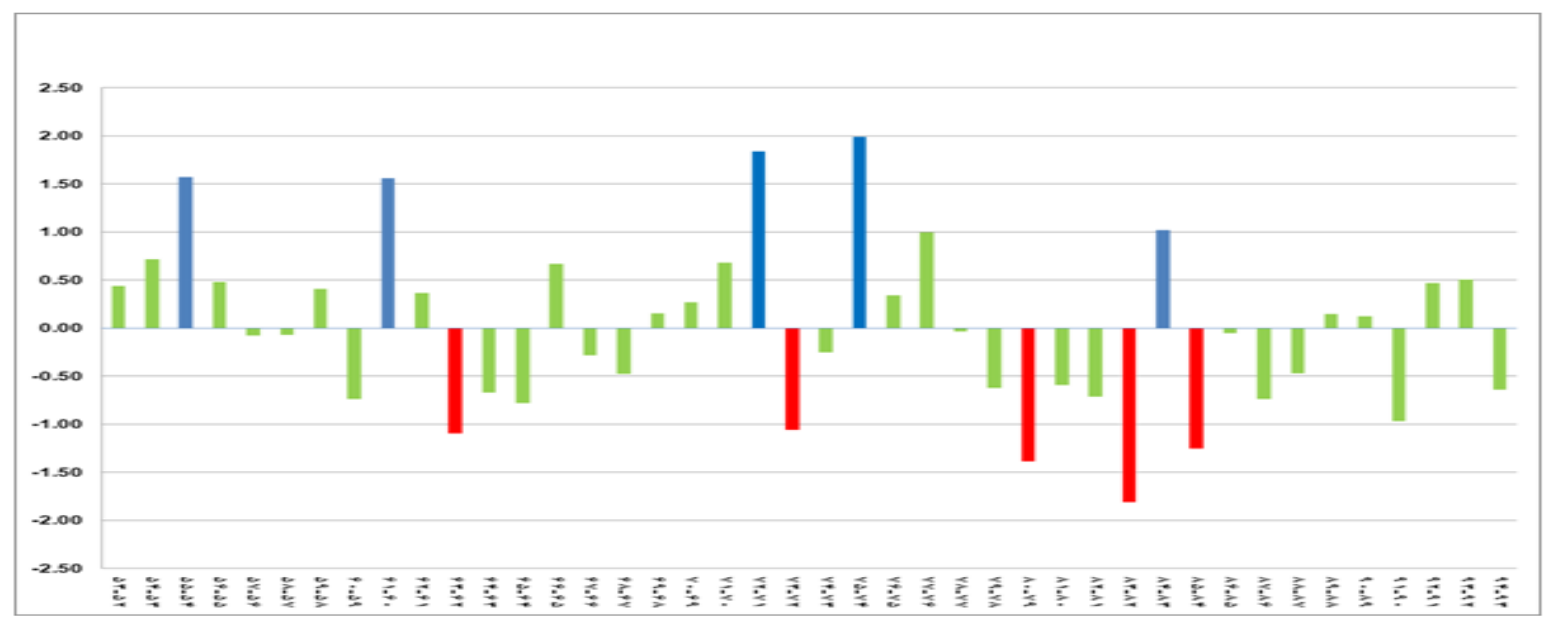

Figure 11: Continuing drought and wet periods in the period in terms of rainfall, Continuing to study the hydrological basin drought Minab .Hydrometric station was used statistics Brntyn. The results are shown in the previous chapter. Monitoring shows that the two types of drought .Hydrological drought and do not necessarily match. For example, although the drought, 2003-2004 years is the severe lack of rainfall. However, this deficiency, two years later, their effect on surface water resources has shown. And the lack of even a wet 2004-2005 year is also not covered.

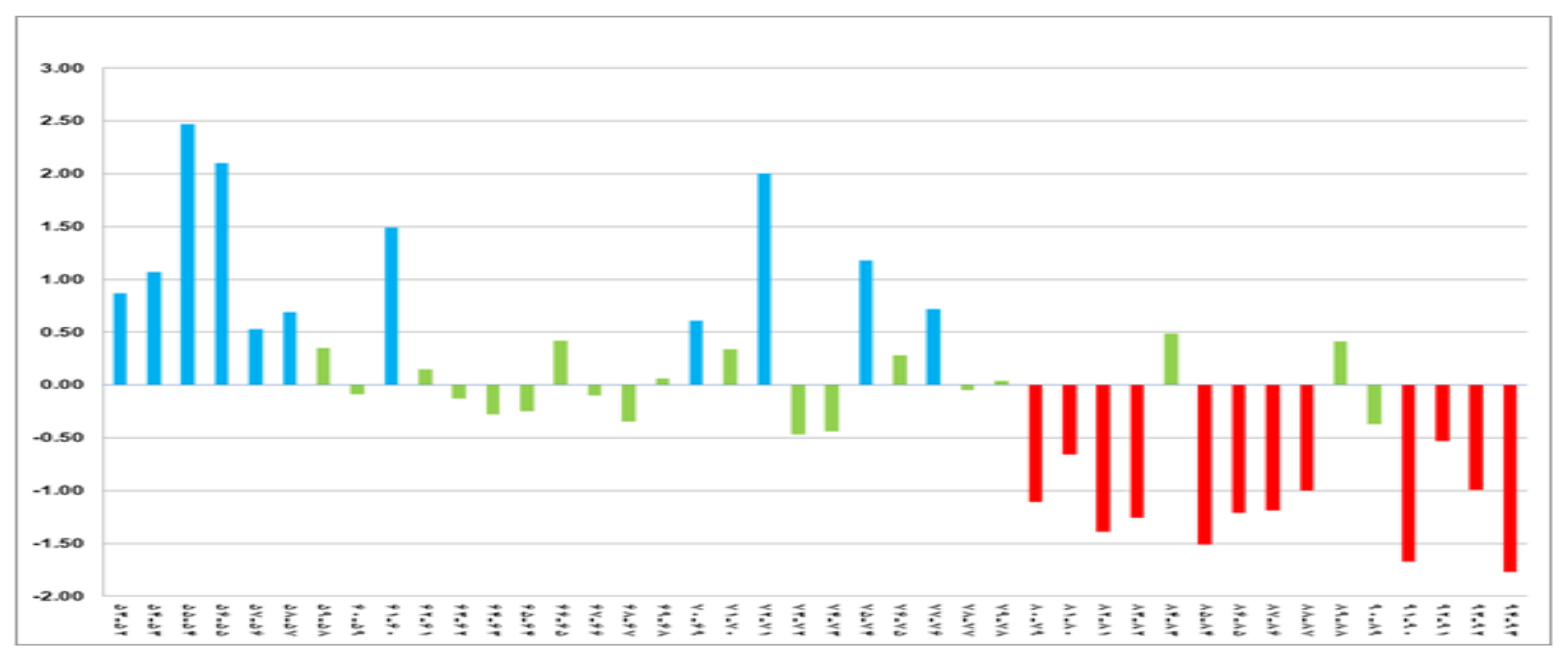

Figure 12: continuation of drought and wet periods in the hydrometric station Brntyn 


\section{REFERENCES}

1. Assadi, M., Zahedan, D, field, 2011. East Azarbaijan modeling precipitation and drought forecasting, climatology National Center for Scientific Bulletin, Issue 2, 8-15. 2. hopes, M, Alizadeh, D, 2009. to study the drought in the province, Geography and Development, Number 51, Pages 51-68.

3. Seeder, 2010. A comparative study of meteorological drought indices of several environmental samples, MA thesis, Tehran University, University of Tehran. 4. Pour-Mohammadi, M., uterine, and, 2014, to recognize and drought forecasting using RDI and SPI indices in Yazd basin, geographical area, number 6: S84-91. 5. parsley, Ser., 1387, statistical analysis of several significant periods of wet and dry climatic zones of Iran using Markov chain, master's thesis, to help Hajjam, Sohrab Tehran University. 6. J, H. And AS. A. Rahimi, 2009, to study the drought situation and trends in East Azerbaijan province which is based on statistical indicators of drought, and builders in Agriculture and Horticulture Research Journal, 64, 2-7.

7. Jamshidi, M., 2009, Statistical Yearbook, Office of Research and Planning. 